\title{
Acties voor Kaapse woningnood
}

AUTEURS Rosalie de Bruijn en Vincent van der Maaden

FOTOGRAFIE Rosalie de Bruijn

De vraag naar huisvesting in Kaapstad overstijgt drastisch het aanbod. Om zich te verzekeren van een dak boven hun hoofd gebruiken woningzoekenden alternatieve strategieën zoals het kraken van leegstaande panden, bekend als "doorkicking", of stichten nieuwe krottenwijken op braakliggende stukken grond. Sociale bewegingen staan deze groepen bij in hun strijd voor betere huisvesting.

Kaapstad is een stad met grote contrasten. Het apartheidsregime dat Zuid-Afrika beheerste tussen 1948 en 1990 (her)lokaliseerde de bevolking volgens ras in strikt gescheiden buurten. De nederzettingen voor niet-blanken lagen vaak ver van de stad, waren slecht bereikbaar en werden afgeschermd door een hek of snelweg. Dit tezamen met de lage investeringen in deze gebieden, maakte het economisch toekomstperspectief voor de bevolking erg somber. Veel gebieden raakte in een negatieve spiraal en werden uiteindelijk onleefbaar. Sinds het eind van de vorige eeuw is van apartheid geen sprake meer, maar de sociale structuur van toen is nu nog overal zichtbaar. Beleidsmakers hebben de gecompliceerde opdracht om de bestaande stad weer leefbaar te maken. Deze al lastige opgave wordt verder bemoeilijkt doordat de bevolking van Kaapstad maar blijft groeien. Dit artikel legt de knelpunten omtrent huisvesting bloot en illustreert hoe de buurtbewoners reageren.

\section{Lay-out van de stad}

Binnen het stedelijke gebied van Kaapstad zijn er duidelijke grenzen zichtbaar: veel bevolkingsgroepen wonen gescheiden van elkaar en ook de voorzieningen zijn oneerlijk over de stad verdeeld. De dynamiek van de stad kan dus per wijk erg verschillen. Het centrum en de aanliggende woonwijken rond de beroemde Tafelberg worden vooral gebruikt door de blanke bevolking van Kaapstad. Zij vinden hier werkgelegenheid, ruime woonwijken en een uitgebreide keuze aan voorzieningen. De arme bevolkingsgroepen wonen ver buiten het centrum, in de schaduw van de Tafelberg. Daar liggen de Cape Flats, een onvruchtbaar gebied waar jarenlang weinig interesse voor was. Wijken gelegen in de Cape Flats zijn nog steeds slecht bereikbaar met het openbaar vervoer en soms is de afstand tot het centrum meer dan 30 kilometer. Tijdens het apartheidsregime was dit de plek waar de onderdrukte bevolking een woning kreeg toegewezen en tot op de dag van vandaag is dit het gebied waar de zwarte en gekleurde bevolking leeft. Veel van hen proberen dagelijks hun geluk te beproeven in het centrum van de stad, maar de kosten voor het vervoer zijn voor sommigen al niet meer op te brengen. De internationale luchthaven van Kaapstad is ook gelegen in de Cape Flats waardoor de snelweg naar het centrum doorheen de uitgestrekte zone van 'townships' loopt. Langs de snelweg richting het centrum zijn veel wijken opgeknapt of aan het zicht onttrokken door omheining, maar daarachter wonen nog honderdduizenden mensen. In het centrum is uiteindelijk weinig te merken van de enorme stad 'achter de Tafelberg'. Vergelijkbare scheidingslijnen zijn typerend geworden voor Zuid-Afrikaanse metropolen.

\section{Elk jaar komen er grote groepen migranten naar de stad met de hoop op een beter leven}

Verstedelijking

Kaapstad heeft de afgelopen decennia een sterke bevolkingsgroei doorgemaakt. Vanaf 1950 is de bevolking vervijfvoudigd tot ruim 3 miljoen inwoners. Elk jaar komen er grote groepen migranten uit Zuid-Afrika en omliggende landen naar de stad met de hoop op een beter leven. De groei van deze migranten concentreert zich vooral in de perifere arme delen van de stad, voornamelijk in de Cape Flats. Deze 


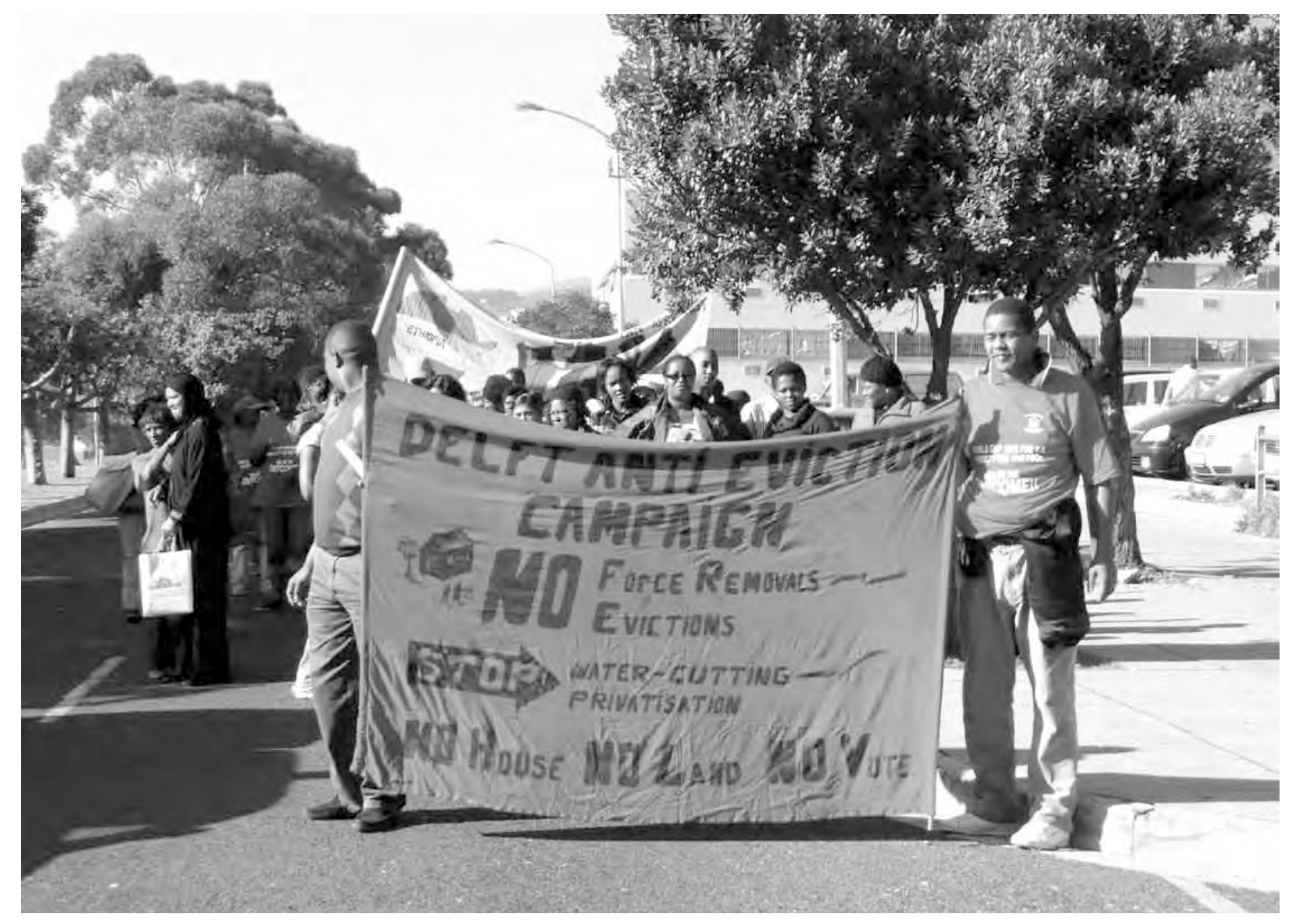

demonstratie Delft AEC

migranten hebben vaak familie of kennissen in de Cape Flats wonen waar zij na aankomst tijdelijk onderdak krijgen. Uiteindelijk bouwen ze vaak zelf een woning voor de lange termijn. Daarbij hebben ze de keuze tussen twee opties. De eerste optie is een krot in de achtertuin bouwen. Deze groep migranten wordt 'backyarders' genoemd. De andere optie is om een krot te bouwen op de onbewoonbare gebieden zoals laag gelegen gebieden die overstromen tijdens zware regenbuien. Dit zijn de informele krottenwijken van de stad. Vaak wordt er gekozen voor de 'backyard' omdat dit veiliger is en toegang biedt tot water en riolering.

In totaal wonen er in de Cape Flats ruim 2 miljoen mensen. Precieze aantallen zijn niet beschikbaar omdat veel mensen in informele woningen wonen - zoals 'backyarders' - en niet geregistreerd zijn. Een telling van de gemeente op basis van luchtfoto's uit januari 2007 wees uit dat er in totaal 108.889 woningen waren in de informele krottenwijken van de stad, meer dan 10\% van de totale woningvoorraad. Betrouwbare cijfers over de bevolking van Zuid-Afrika zullen pas in maart 2013 beschikbaar zijn. Dan zullen de uitkomsten van de volkstelling van dit jaar bekend worden, ruim 12 jaar na de vorige.

\section{Huizencrisis in Kaapstad}

Het nationale huizentekort wordt geschat op 3 miljoen woningen. Met de realisatie van 265.000 woningen per jaar door de overheid zal het nog vele jaren duren om het huidige tekort op te lossen en daarbij is de groei van de woningvraag nog niet meegerekend. Voor Kaapstad wordt het huizentekort op 400.000 woningen geschat. Dit aantal groeit jaarlijks met ongeveer 23.000 vanwege migratie en natuurlijke groei. Om al deze woningzoekenden te registreren zijn er wachtlijsten opgesteld, maar deze registratie methode is niet te vergelijken met de Nederlandse of Belgische sociale woningbouw. In Kaapstad is het voor woningzoekenden erg onduidelijk hoe hoog zij op de wachtlijst staan en wanneer zij een woning krijgen toegewezen.

\section{in de voormalige kleedkamers van het Athlone stadion zijn zes wooneenheden gemaakt}

Net als op nationaal niveau, worden er in Kaapstad te weinig woningen gerealiseerd om het tekort terug te dringen. In 2008 zijn er 9.576 huizen opgeleverd. Met dit tempo van oplevering neemt het huizentekort van de stad toe met 14.000 per jaar. Let wel, dit is het geregistreerde tekort. Wanneer de vraag van 'onzichtbare groepen' zoals 'backyarders' wordt meegenomen, zal het woningtekort nog groter 
zijn. Op dit moment heeft namelijk gemiddeld 7 van de 10 huishoudens een familie in hun tuin wonen. De verwachting is dat dit nog verder zal toenemen naar twee families in elke tuin binnen 10 jaar. Uit eigen onderzoek in 2009 in de formele 'township' Delft South is er blijk van verdichting. Alleen al van de woningen die in 2000 zijn opgeleverd, blijkt 89\% in 2009 een 'backyard' woning te hebben. De vele backyard woningen zorgen ervoor dat er een toenemende druk ontstaat op de ruimte, voorzieningen en veiligheid. De leefbaarheid van bestaande wijken staat zelfs op het punt te bezwijken onder deze druk. Ondanks dat er duidelijk sprake is van een huizencrisis in Zuid-Afrika, wordt maar 1,5 procent van het nationale budget besteed aan huisvesting vergeleken met 5 procent dat uitgegeven wordt in de meeste andere ontwikkelingslanden.

\section{Onrust in de stad}

Sinds de afschaffing van de apartheid zijn er veel inspanningen gedaan op het gebied van huisvesting, maar van een zichtbare verbetering is geen sprake. Hoewel vele ambitieuze programma's zijn opgezet om in een korte periode niet alleen nationaal 1 miljoen huizen te bouwen maar ook om achtergestelde wijken van voorzieningen te voorzien, is dit niet gerealiseerd. De overgang van een sociaal naar een neoliberaal beleid zorgde ervoor dat basisvoorzieningen zoals huisvesting die voorheen onder de verantwoordelijkheden van de overheid vielen, tegenwoordig vooral door particuliere bedrijven worden verzorgd. Deze transitie heeft verschillende spanningen teweeg gebracht onder andere op vlak van water- en elektriciteitsvoorziening. Jarenlang waren deze voorzieningen gratis beschikbaar voor de armste groepen van de samenleving, maar deze voorzieningen zijn langzamerhand door de overheid geprivatiseerd. Dit betekent dat in steeds meer bestaande en nieuwe woongebieden in de Cape Flats 'prepaid' voorzieningen worden geïnstalleerd, oftewel systemen waarbij bewoners vouchers moeten kopen om directe toegang tot deze voorzieningen te krijgen. Dit heeft ervoor gezorgd dat de prijzen voor water, elektriciteit en huur gevoelig verhoogd zijn. Als gevolg hiervan kunnen veel arme huishoudens de kosten niet meer opbrengen en worden zij vaak afgesloten van water en elektriciteit en soms zelfs uit hun huis gezet. Dit heeft geleid tot grote onvrede onder de bevolking van de Cape Flats.

\section{'Grassroots' acties voor huisvesting}

Om de huisvestingsproblematiek en beperkte toegang tot basis voorzieningen weer hoog op de politieke agenda te krijgen, zijn er vanaf het jaar 2000 vele sociale bewegingen en actiegroepen opgericht. Sociale bewegingen en wijkcomités roepen om alternatieven. Zij pleiten voor een samenleving waarin burgers die een huis bezitten niet angstig hoeven te zijn voor ontruimingen en afsluitingen van basisvoorzieningen. Daarnaast pleiten zij voor het ontwikkelen van gebieden waarin mensen al generaties lang wonen, in plaats van groepen mensen te verplaatsen naar nieuwbouwprojecten aan de rand van de stad, ver weg van hun sociale netwerken, werkgelegenheid en goede scholen. Tot slot pleiten zij voor erkenning van hun mensenrechten en voor het waarmaken van eeuwige beloftes van politici om huisvesting in de nabije toekomst te realiseren. Een voorbeeld hiervan is de Western Cape Anti-Eviction Campaign (AEC) in Kaapstad. Deze sociale beweging zet zich in om bewoners van de Cape Flats bij te staan in hun strijd tegen ontruimingen. In de jaren dat deze beweging actief is, heeft zij veel gezinnen bijgestaan in de strijd voor hun 'thuis' door middel van juridische hulp, informatieve bijeenkomsten, massaprotesten en directe acties bijgestaan Een veelvoorkomende ingreep van de AEC is het kraken van woningen van families die zijn uitgezet. Vaak worden dan ook illegaal de basisvoorzieningen weer aangesloten.

\section{Het heft in eigen hand nemen}

Door de enorme huizencrisis zoeken sommigen groepen mensen naar alternatieve woonvormen zoals de 'backyarders'. Een veel gebruikte tactiek is het kraken van leegstaande panden. Een voorbeeld hiervan is een oud schoolgebouw in het district Athlone dat door 366 'backyarders' in beslag is genomen en daarna is omgevormd tot woningen. Enkele straten daar vandaan zijn zes families in de voormalige kleedkamers van het Athlone stadion getrokken en hebben zij hier zes wooneenheden van gemaakt. Alhoewel deze oude gebouwen voorzien zijn van stromend water en riolering, ontbreekt er elektriciteit en leven gezinnen veelal gezamenlijk in een ruimte, zonder enige vorm van privacy. Er bestaat in Kaapstad zelfs een groep die 'doorkickers' wordt genoemd en die nieuwbouw woningen kraakt om snel aan huisvesting te komen.

Een ander voorbeeld om aan huisvesting in de buurt van voorzieningen te komen is om een leeg stuk grond dat toebehoort aan de gemeente te bezetten en daar illegaal krotten op te bouwen. De personen die dit proberen komen uit overvolle 'townships' waar geen ruimte meer is om een krot op het erf van een ander te bouwen. Omdat er geen alternatieven zijn, gaan deze personen over tot de bezettingen van land, of 'land invasies', zoals de overheid het noemt. Door het ontbreken aan alternatieven is dit soms de enige uitkomst voor families.

Als een stuk land eenmaal bezet is, mag de overheid deze 'squatters' niet zomaar ontruimen. Hoewel deze krakers via de wet beschermd worden tegen illegale ontruimingen, oftewel ontruimingen zonder de groepen alvorens te informeren en zonder eerlijk proces, worden deze land invasies momenteel hard aangepakt door de overheid. Speciale 'anti-land invasie' eenheden worden ingezet om lege percelen 24/7 te controleren en zodoende landinvasies te voorkomen. Als landinvasies desondanks hebben plaatsgevonden nemen deze eenheden juridische maatregelen en worden pogingen tot uitbreiding van de krottenwijk hard neergeslagen. Nieuwe krotten worden vernield, mensen gearresteerd en anderen weer terug geplaatst naar waar zij vandaan kwamen. Met dit beleid probeert de stad te voorkomen dat nieuwe krottenwijken verschijnen. De gemeente ziet landinvasies als een overtreding van de wet en als illegale acties om bovenaan de wachtlijst voor huisvesting te komen. Reeds gebouwde krotten mogen namelijk niet zomaar ontruimd worden zonder alternatieve huisvesting aan de daklozen bewoners te bieden.

\section{Conclusies}

Met 400.000 nieuwe woningen zijn de problemen van de bewoners in de Cape Flats nog niet opgelost. Wanneer zij na jaren te hebben gewacht een nieuwbouwhuis mogen betrekken, ervaren zij nog vele problemen. Deze huizen liggen soms wel 35 kilometer van het centrum, 


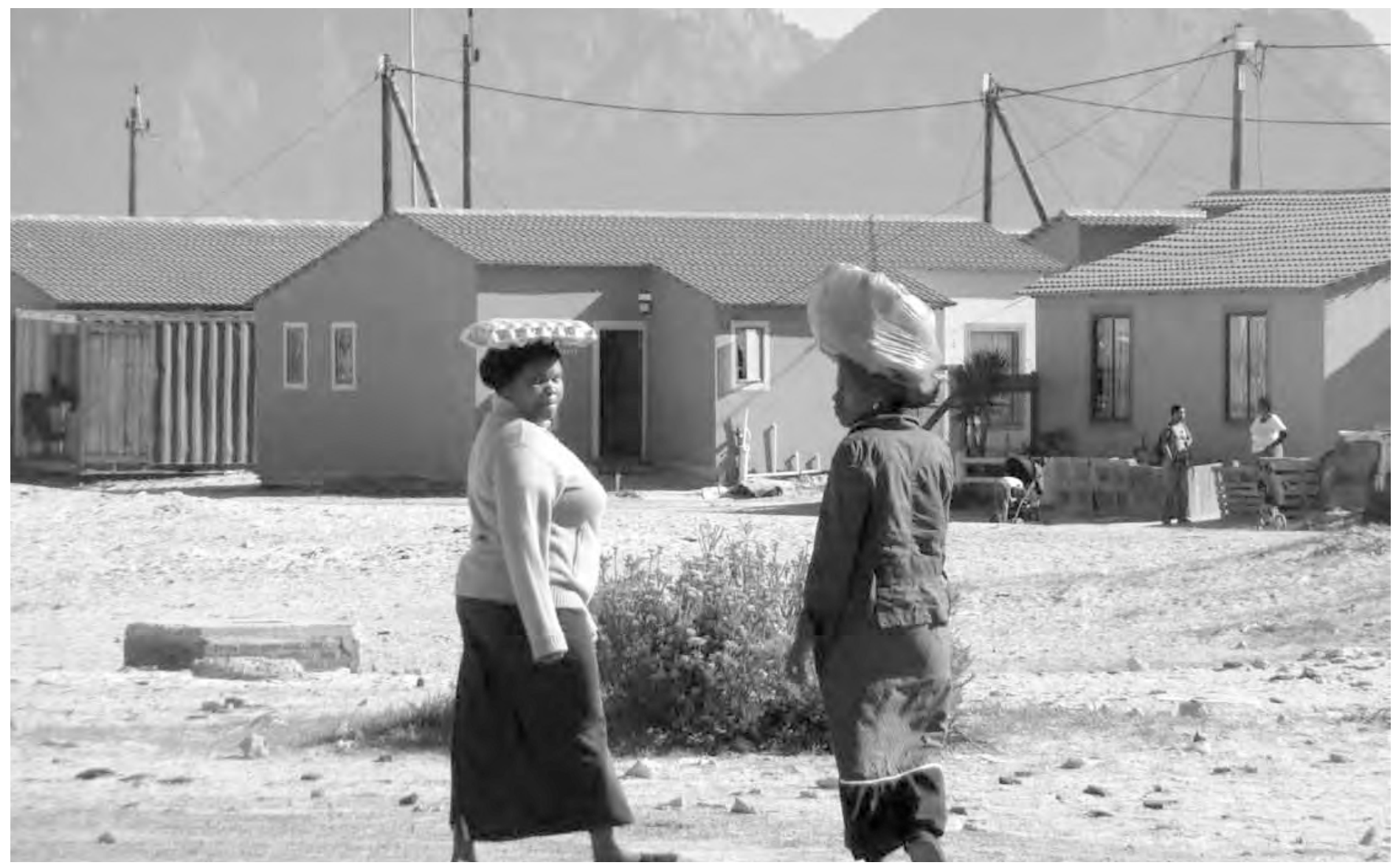

Nieuwbouw woningen in Delft, aan de rand van de stad

ver weg van werkgelegenheid en diverse voorzieningen. Vanwege de beperkte financiële middelen van de bewoners van deze nieuwbouwwijken is het lastig om deze grote afstanden te overbruggen en in hun dagelijks levensonderhoud te kunnen voorzien. Daarnaast is ook in deze nieuwe wijken sprake van veel criminaliteit. De droom van het bezitten van een huis en het hebben van een beter bestaan staat ver weg van de harde realiteit in Kaapstad.

In onze visie staat de overheid te ver van de bewoners vandaan en is het beleid dat zij voeren niet duurzaam. Gemeenschappen zouden gestimuleerd moeten worden om hun eigen woonomgeving te ontwikkelen tot een duurzame leefomgeving . Voorwaarde hiervoor is wel dat de overheid basisvoorzieningen levert en grond beschikbaar stelt. Het toekomstige huisvestingsbeleid moet zich dus niet alleen richten op kale woningbouw, maar moet allesomvattend zijn en gerealiseerd worden in samenwerking met de buurtbewoners.

\section{Rosalie de Bruijn (rosaliedebruijn@msn.com) is recentelijk} afgestudeerd in de Sociale Geografie aan de Graduate School for Social Sciences en Vincent van der Maaden (Vincent. vanderMaaden@student.uva.nl) is Master student Sociale Geografie aan de Universiteit van Amsterdam en Aardrijkskundeleraar.

Dit artikel is gebaseerd op veldwerk dat beiden voor hun afstudeeronderzoek hebben verricht in 2009 en 2010.

Tot slot is hier ook een woord van dank aan Ellen Van Hoeck op zijn plaats, aangezien dit artikel mede gebaseerd is op onderzoek dat zij verricht heeft binnen MOSI-T.

\section{Literatuurselectie}

Anti-Eviction Campaign Western Cape (2008) About Us. Beschikbaar via: http://antieviction.org.za/about-us/

Legassick, M. (2008) Western Cape Housing Crisis: Writings on Joe Slovo and Delft, A Western Cape Anti-Eviction Campaign and Socialist Alternative publication. pp. 1-47. Beschikbaar via: http://westerncapeantieviction.files. wordpress.com/2008/03/joeslovo_delft-leggasick.pdf Lemanski, C., 2009, Augmented informality: South Africa's backyard dwellings as a by-product of formal housing policies, Habitat International, 33.4, pp $472-484$

Lemanski, C. en S. Oldfield (2009) Parallel Claims and Polar Responses? Gated Communities and Land Invasions in a Southern City: Polarised State Responses, Environment and Planning A, 41(3): pp 634-648.

Oldfield, S. and, K. Stokke (2004) Building unity in diversity: Social movement activism in the Western Cape Anti-Eviction Campaign. Beschikbaar via: http:// www.nu.ac.za/ccs/files/Oldfield\%20\&\%20Stokke\%20WCAEC\%20Research\%20 Report.pdf 